\title{
A VALUE MANAGEMENT FRAMEWORK FOR GREEN DIGITAL MARKETING PROJECT
}

\author{
Anass Zaidouni \\ ENSIAS, Mohamed V University -Souissi \\ BP. 713, Agdal, Rabat, Morocco
}

\begin{abstract}
Nowadays, Digitalization and Sustainability are perceived as Value Drivers by organizations. Previously, literature has addressed Value Management (VM), but never has it assessed the precedent drivers' benefits. Throughout this paper, the theoretical background is explored, deriving effective methodologies, processes and techniques for value measurement in the project Performance Management, and then articulating a VM Framework for the Green Digital Marketing Project. The constructed methodology integrates a value process and value techniques, and leverages certain $\mathrm{MoV}^{\mathrm{TM}}$ guidance principles. Meanwhile, risk inherence is addressed in the value appraisal enabling decision makers and practitioners to cope with uncertainty related to the two drivers. Stated implications are generalizability, principles embeddedness and decision-making aid.
\end{abstract}

Keywords- Value Management, Digitalization, Sustainability, Project and Performance Management, Risk Management, Green Digital Marketing

\section{INTRODUCTION}

Value thinking is considered a rich Theory of Value Management concepts, methodologies, processes and techniques (Miles, 1989; Thiry, 1997; Kelly, Male, and Graham, 2015), standards such as the SAVE International standard (SAVE, 2007) $\mathrm{MoV}^{\mathrm{TM}}$ best practices guidance (Axelos, 2010) and several VM related studies.

The richness of the current literature reflects an arisen value awareness of practitioners, and decision-makers in addition of the benefits behind leveraging the values of the change initiatives in the core operations of the organizations. In parallel, the field of Information Technology (IT) has not only evolved but also disrupted towards what it is called "Digitalization" or "Digital Transformation", which becomes a first priority for organizations to embrace the change and achieve performance (Manavalan and Jayakrishna, 2018; Boulton, 2019). Additionally, Sustainability has been an imperative issue nowadays, thus organizations are struggling to implement different strategies for its adoption. In one part, organizations aim to maximize their Return of Investment

\author{
Mohamed Abdou Janati Idrissi \\ ENSIAS, Mohamed V University -Souissi \\ BP. 713, Agdal, Rabat, Morocco
}

(RoI) due to sustainable activities incorporation into (Phillips \& Phillips, 2013), and, in another part, to sustain environmental and social policies in their production chains of products and services (Fearne, Garcia, \& Dent, 2012; Buxel, Esenduran, \& Griffin, 2014).

This paper aims to present a methodological study of the articulation of Value Management Framework with a value process and a set of techniques to appraisal the monetary, strategic, societal and regulatory benefits of Digitalization and Sustainability in a Utility Green Digital Marketing Project while taking into account risk and uncertainty in the value assessment. This paper is intended to managers, decision-makers and VM skeptical practitioners about how much value their digital green marketing or any type of project will yield. The target Framework is mainly characterized by generalizability to other types of initiatives, scalability to adopt any value technique, pertinent principles incorporation, and decision-making aid.

The rest of the paper is organized as follows. Literature Review is firstly undertaken in section II, then the proposed methodology is built up emphasizing on the rationale behind the VM Framework construction in section III. To sum up, a conclusion is given with future perspectives.

\section{LITERATURE REVIEW}

\section{A. Digitalization}

Boulton (2019) defines Digital Transformation as a thorough change in how an organization delivers value to its customers through a drastic redesign of the organization in her way to use technology, staff and processes to shift business performance. In another hand, Big Data is defined as huge amounts of data generated from different structured and unstructured sources (Pappas, Mikalef, Giannakos, Krogstie, \& Lekakos, 2018; Manavalan and Jayakrishna, 2018). Moreover, Pappas et al. (2018) state that Big Data and Analytics, as the best value-scoring digital pillars, contribute effectively to monetize data and boost competitiveness. Lavalle, Lesser, Shockley, Hopkins, \& Kruschwitz (2011) demonstrate the value of analytics via the following findings of their survey, conducted with IBM Institute for Business Value: 


\section{International Journal of Engineering Applied Sciences and Technology, 2019 Vol. 4, Issue 8, ISSN No. 2455-2143, Pages 56-62 \\ Published Online December 2019 in IJEAST (http://www.ijeast.com)}

- Organizational performance using analytics is 5 times more than without analytics;

- Widespread audience relies on Analytics as a Value driver $(0.5$ of the audience says that analytics was a first priority with 1:5 were obliged to embrace the analytics approaches) and involves market demarcation with the penetration of this innovation (Confirmed by 6:10);

- With the same statistic of half the audience, the more data the organization embraces the more it can harness. The data growth would be supported by this disruptive technology, which is analytics.

Manavalan and Jayakrishna (2018) define IoT as an inherent, performing and scalable technology that involves Digital Transformation of the connected world via internet and transmit the real time information throughout the whole value chain, bringing smartness to operations. In Marketing, Tiago and Verissimo (2014) state decision-making support, productivity and better outcome measurement as benefits of digital marketing Medias in the way of fostering the company brand and acquiring the competitive advantage through digital marketing engagement. Van Velthoven and Cordon (2019) draw the attention to the fact that sustainable innovation in Healthcare is involved by patient satisfaction and job protection. Alfian et al. (2019) devise the Digital Signage based Online Store (DSOS) aiming to extrapolate decisions and recommendations on green purchasing and marketing, sustainability, effective attractiveness and loyalty of customers, continuously efficient quality service's amelioration and competitive advantage of retailers over their competitors. This system is based on real-time big data processing and association rules that use customer behaviors patterns. With the advent of Digitalization to Utilities, Sánchez, Elicegui, Cuesta, Muñoz, \& Lanza (2013) enumerate IoT network, Utility smart grid, analytics, automation, autonomous street lighting and real-time information as smart cities capabilities to pave the path towards sustainable development in a Future Internet (FI) architecture. In the same field, Cook et al. (2012) estimate the smart metering and Realtime pricing model rollout related Net Present Value (NPV), for a 15 years period and with a $7 \%$ discount rate, to $\$ 436$ billion, against costs of $\$ 45$ billion concerning the residential households. It is an evidence that proves that the smart meter implementation cost is low compared to benefits, such as responsiveness, electricity demand elasticity, and real-time pricing monitoring (valuable to both the customer and to the Utility).

It can be concluded the following Value Drivers:

- Smart meter: Smart metering is an evolving technology. Energy consumption' meter reading is without human intervention thanks to automation and IoT;

- Make intelligent decisions based on huge data sets;
- Integrate real-time solutions: It consists on the actualized system responsiveness to the information requests;

- RoI maximization is also an important factor involved by business digitalization.

These Value Drivers will foster any product or service and will enrich the cultural background about Digitalization in the move towards its adoption by the organization.

\section{B. Sustainability}

Not only customer engagement is driven by innovative systems but also by the sustainable means. Kohl (2016) states that among the factors behind a product or service appealingness is the sustainable values it holds, boosting the customer engagement. Carvalho and Rabechini (2017) show positive correlations between sustainable projects and their success and low commitment to social and environment aspects in the projects. Engert, Rauter, \& Baumgartner (2015) perceive strategic management as a mean of integrating corporate sustainability into the organization strategy and a Framework of issues, positive factors and impediments is built up for its adoption. Furthermore, Silvius and Schipper (2015) explore the Sustainability impact on project success in a conceptual model, and result that stakeholder satisfaction, future readiness and controlled project execution are the bestcorrelated project success criteria.

From this walkthrough, it can be stated that Sustainability is not only a key issue of todays, but also it is key valuable dimension that need to be leveraged.

\section{Value Management}

Literature has evocated many value methodologies and techniques praising their advantages in the performance management of the organization. According to Kelly et al. (2015), a value study, in the form of VM or Value Engineering (VE), can supervene at any phase of the project and proposes different techniques, led by a Value Study Leader (VSL) and structured by the phases: Orientation and Diagnostics, Value Workshop and Implementation. Kelly et al. (2015) states that the value study performs, at the project level, an explicit appraisal of the functional benefits of a project in accordance with a Client Value System. Moreover, Management of Value $\mathrm{MoV}^{\mathrm{TM}}$ guidance (Axelos, 2010) scrutinizes different approaches to achieve the project objectives in order to maximize the RoI. This guidance proposes seven stepped processes to direct the organization towards the identification of the best VfM project alternative (Axelos, 2010). These processes are:

1- Frame the project: It consists on apprehending the organization objectives;

2- Gather information relating to the project: Stakeholders requirements and interests are understood in a value study led by the study leader; 


\section{International Journal of Engineering Applied Sciences and Technology, 2019 Vol. 4, Issue 8, ISSN No. 2455-2143, Pages 56-62 \\ Published Online December 2019 in IJEAST (http://www.ijeast.com)}

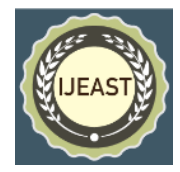

3- Analyze information: Value techniques are used to answer the following questions, "What" and the "How" through the least or the best costy functionperforming alternatives;

4- Process information: The study team examines, in an iterative way throughout workshops, project proposals trying to enhance its value by either integrating worthwhile functions or dropping out the not needed ones;

5- Evaluate and select: to select the most value-adding proposal, Value Drivers are appraised for the different project's alternatives. The value is defined as the ratio of satisfaction of needs over resources utilization.

6- Develop value-improving processes: Implementation of the selected ideas by the study team is undertaken. Value Management is seen as a mean of decisionmaking aid;

7- Implement and share outputs: Planning of the best value-performing contract is undertaken. A benefit management process, with the same techniques used in the value appraisal, need to be set up to track down anytime the discounted value and take on corrective actions.

Khodeir and El Ghandour (2019) demonstrate that through the application of a VM methodology, cost overruns can be controlled, which results to a $15 \%$ to $40 \%$ savings of the total Residential projects costs in Egypt. Moreover, the application of value engineering SAVE based approach and sustainable practices to a residential project improves the thermal performance or R-Value from $20 \%$ to $30 \%$ proving the VE cost-effectiveness and sustainability impact according to Rachwan, Abotaleb, \& Elgazouli (2016). Yu, Javed, Lam, Shen, \& Sun (2018) see Value Management as a strength using the SWOT analysis, and state that it is beneficial for different stakeholders regarding society and the environment concerns.

There are several techniques used in Value Management to assess value. Kelly et al. (2015) cite evoke that the Client or Strategic Function Analysis Systematic Technique (FAST) diagramming is used to modelize the project purpose and objectives in a primary and related functions of a component. It is a project function break down decomposing the product or service into detailed functions lays out a systematic and innovative approach to brainstorm and select the best functions for improving value. To illustrate the utilization of FAST diagram, Berawi et al. (2014) provide innovative functions elaborated for the SHIARL related PRASTI tunnel project, with experts' involvement and benchmarking, this FAST diagram enables to reduce the Internal Rate of Return (IRR) and NPV of this project and prevent floods in Jakarta. Blumstein (2011) views FAST as a technique that speeds up customer needs and expectations collection and measurement due to its many benefits: differentiation, customer centricity, cost avoidance of customer non-satisfaction, customer loyalty and change ability.

There is also the Value for Money calculated as the ratio of the value score of the Value Drivers by alternative cost, this technique is preceded by Simple Multi Attribute Rating Technique (SMART) or Value Tree, Value Profiling, and Value Index calculation as stated by Axelos (2010). SMART or Value Tree consists of a decreasing abstraction from left to right hierarchical tree (project name is the root) when answering how to deliver the project objective in simple value adding attributes from left to right. In turn, each of the attributes is broken down to value-adding attributes to that branch of the hierarchy (Axelos, 2010; Kelly et al., 2015). In this technique, Client team can rank the value adding attributes in order of their performance in fulfilling the project objectives by a weight less than one. Then, according to Axelos (2010), a cost is assigned to the value tree in order to assess the cost of performing a function relatively to the whole project. Afterwards, the value profile is established then the value index is calculated as the product of weight and the performance (scale from 0 to 10) of the Value Driver (Axelos, 2010).

Regarding the study team weighting exercise, there are many techniques to perform the weighting. The problematic of weights revolves on their likelihood to reflect real relative importance of attributes or criteria, thus these weights are called "swings". To cope with this issue, surrogate weights are proposed to convert real weights to take into account the swing. Roberts and Goodwin (2002) state that the Rank Order Distribution (ROD) weights are the best approximation of the true weights according to a comparison study between ROD, Rank Order Centroid (ROC), Rank Sum (RS) and Rank Reciprocal (RR) surrogate weights' efficacy. ROD surrogate weights or means present a workaround to shrink the ROC weights extreme value ratio (Roberts and Goodwin, 2002). Their elicitation is performed via Direct Rating. The ranges of the possible 'raw' weights will be: $w_{1}{ }^{*}=100,0<w_{2}{ }^{*} \leq 100,0<$ $w_{3}{ }^{*} \leq w_{2}{ }^{*}$, and, in general, $0<w_{i-1}{ }^{*} \leq w_{i}{ }^{*}$ where $i \neq 1$. Once the 'raw' weights $w_{i}{ }^{*}$ are produced then they are normalized to sum to 1. Roberts and Goodwin (2002) apply the probability density distribution functions equations for the normalized weights to compute the surrogate weights.

Another value technique is the WLV conceptual model (Kelly et al., 2015). The Whole Life Value (WLV) is the Value Thinking theory that perceives value spanning the whole life of an asset from inception, design, implementation, and maintenance phases. The WLV conceptual model is seven phased, which are Context and inception, Strategic briefing, Development of the WLV conceptual model, The numerical form of the conceptual model, The logic of the WLV conceptual model, Option development, option appraisal and the strategic outline case and Goal and systems modelling (Kelly et al., 2015). Kelly et al. (2015) state that comparison between VfM and WLV factor is still possible because they are on the same measurement scale . At the strategic briefing, 


\section{International Journal of Engineering Applied Sciences and Technology, 2019 Vol. 4, Issue 8, ISSN No. 2455-2143, Pages 56-62 \\ Published Online December 2019 in IJEAST (http://www.ijeast.com)}

the function analysis and the Client Project Value System are elaborated (Kelly et al., 2015). The Client Project Value System is nine facets matrix representing the organization value perspectives (Kelly et al., 2015). Then, the numerical form of the conceptual model phase consists on weighting the Client Project Value System matrix by the Client team using a 5-point Likert scale and either, the simple Paired Comparison (Kelly et al., 2015), or the Analytic Hierarchy Process (AHP) devised by Saaty (1980) in the strategic briefing meeting. A proportional weighting for all facets then a proportional adjusted weighting for the functional facets, except capital cost and operational or operating cost, are then undertaken. Afterwards, the weighting of the FAST diagram is effectuated. Whilst the Development of the WLV conceptual model phase, the forecast alternative WLCs is adjusted to consider the alternative non-completion risk at time. At the option appraisal, the Client team realizes the rating of Costs and time facets and Value. Capital cost factor, Operating cost factor and WLC index are then calculated. Finally the Value index, Function index, benefit index and WLV index or factor are calculated.

The following table synthetizes the best effective value techniques reviewed in literature.

Table -1 Value techniques benefits

\begin{tabular}{|c|c|}
\hline Technique & Advantage \\
\hline Client or Strategic FAST & $\begin{array}{l}\text { - Function orientated; } \\
\text { Systematic and innovative approach to } \\
\text { brainstorm and select the best functions } \\
\text { for improving value. }\end{array}$ \\
\hline Value for Money & $\begin{array}{l}\text { - Possibility to benchmark the project } \\
\text { against different alternatives having the } \\
\text { same objectives; } \\
\text { - Metric to compare alternatives based on } \\
\text { the ratio of value to cost, when taking } \\
\text { into account the value of fulfilling the } \\
\text { functional requirements against their } \\
\text { costs in each alternative; } \\
\text { - Provides the value for money aggregated } \\
\text { per the different Value Drivers earlier at } \\
\text { the project strategic briefing } \\
\text { - Enables to reallocate appropriately } \\
\text { resources to enhance value among the } \\
\text { project objectives; } \\
\text { Maximizes quality in detriment to the } \\
\text { Whole life Costs (WLCs) of the product } \\
\text { or service at a minimum resources } \\
\text { utilization }\end{array}$ \\
\hline WLV conceptual model & $\begin{array}{l}\text { - Appraisals project value from kickoff to } \\
\text { handout considering Whole Life Costs } \\
\text { (WLCs) as capital investment with time } \\
\text { factor, and NPV for the asset impact over } \\
\text { a study period that starts from the } \\
\text { handout date; } \\
\text { - Informs the project brief via the WLV } \\
\text { factor as a KPI to aid decision-making on } \\
\text { the alternative feasibility from a value } \\
\text { basis. } \\
\text { KPI that reflect the relationship between } \\
\text { the stakeholders confidence degree about } \\
\text { the realization of the whole life benefits }\end{array}$ \\
\hline
\end{tabular}

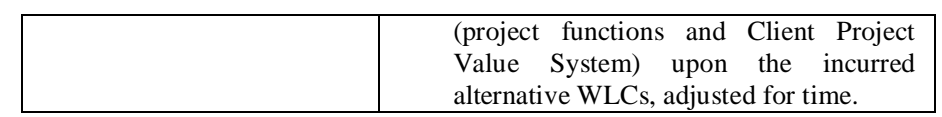

\section{PROPOSED METHODOLOGY}

From the depicted problem, conceptualizing the research design enables to elaborate the Value Management Framework for the "Green Digital Marketing Project".

\section{A. Rationale}

For its simplicity, openness and smoothness, $\mathrm{MoV}^{\mathrm{TM}}$ value processes are the best suiting to the context of an organization willing to lighten its processes. In addition, the adoption of some principles preconized by this guidance is opportunistic, such as alignment with organization objectives, function focalization, whole life project application, tailoring and learn from experience and continuous improvement. The resulting methodological VM Framework (Figure 1) entails a seven stepped value process and specific $\mathrm{MoV}^{\mathrm{TM}}$ principles.

The selected set of techniques, within the target VM Framework, are:

- Value for Money;

- Whole Life Value conceptual model based on Client Project Value System.

From one part, Value for Money is seen an efficacious technique for the following reasons:

- Operates on project objectives considered as Value Drivers;

- Abstracts the project alternatives and focuses just on the values of the project objectives;

- Evaluates the tangible and intangible benefits from earlier before project start, and can applied furthermore to monitor value;

- $\quad$ Provides a value baseline for further benchmarking.

It ought to be assumed that Value Drivers of a project may evolve and change in relative importance during the project execution from a value perspective. Therefore, the associated risk should be taken into consideration in the weights given to the Value Drivers in the Value Profiling weighting exercise. The Value Drivers are attributed the surrogate weights by the study team in accordance with their importance, as long as these weights best approximate the true weights, and at the same time, cope with the variability of the attributes in SMART method.

Departing from the most life-lasting value impact objective, the WLV conceptual model is adopted in the set of techniques in the VM Framework for the following reasons:

- Setting up a Client Project Value System of facets, able to generalized after for other kinds of projects. Thus avoiding any interpretation or bias by the study 


\section{International Journal of Engineering Applied Sciences and Technology, 2019 \\ Vol. 4, Issue 8, ISSN No. 2455-2143, Pages 56-62 \\ Published Online December 2019 in IJEAST (http://www.ijeast.com)}

team and setting up a facet driven roadmap for virtuous value for the organization. simple Paired Comparison is advocated over AHP for its simplicity;

- Client assessment of functional benefit, value and time;

- WLV evaluation is twofold capital and operational investment;

- End to end project change in the operational level then if case of any business change, the need of new project arises thus monitoring the virtuous value wheel;

- WLV factor is a metric at the strategic briefing workshop to which other proposals can be assessed on the same scale of value for money;

- Gain in efficiency and effectiveness during project development and the through life exploitation.

\section{B. Value Management Framework}

The final VM Framework is given in Figure 1. The Value For Money and WLV conceptual model (Figure 2) are used as value techniques in the step "3-Analyze information" of the process.

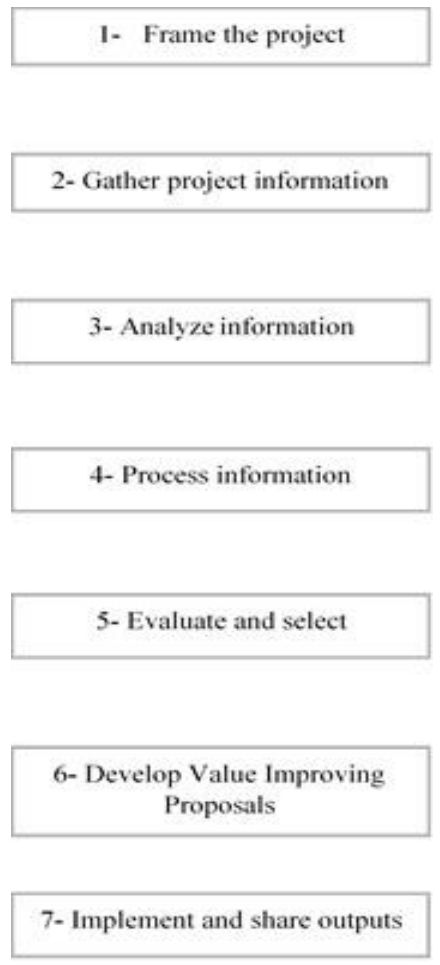

Fig. 1. Articulated VM Framework $\left(\mathrm{MoV}^{\mathrm{TM}}\right)$, Adapted from Management of Value $\left(\mathrm{MoV}^{\mathrm{TM}}\right)$, by Axelos, 2010, London, England: TSO. Copyright (C) AXELOS Limited 2010. Used under permission of AXELOS Limited. All rights reserved.
1- Context and inception

2- Strategic briefing

3- Whole- life Value calculation

4- Whole-life Value factor KPI

5- Project option appraisal

Fig. 2. WLV conceptual model. Reprinted from Value Management of Construction Projects (2nd ed.), by J. Kelly, S. Male, and D. Graham, 2015, John Wiley \& Sons. Copyright 2015 by John Wiley \& Sons.

Through this methodological paper, it is possible to shed new light on the applicability of a tailored Value Management Framework to two key strategic Value Drivers in organization, which are Digitalization and Sustainability. As well, the risk surrounding value appraisal is addressed from two perspectives: the value at completion and the whole lifespan value.

For the Utility, it is a mean to engage on the digital era, creating growth and boosting Marketing activities and demarcation.

\section{CONCLUSION AND FUTURE PERSPECTIVES}

The research question that this paper tackles is about devising a Value Management Framework that assesses Digitalization and Sustainability in Project Management, forecasting a value based Performance Management whilst providing risk exposure measurement in the value appraisal for the context of a Utility Green Digital Marketing Project. Particularly, the VM Framework consists of a value process and two value techniques to assess value according to two risk dimensions, inherent risk of drivers weighting variability from one part, and the risk at time through the lifespan operation from a second part.

A part from the theoretical implication of this paper, the established holistic VM Framework will ensure a full Value thinking embeddedness into the Marketing operation with many principles and a value-oriented culture instilled to personal due to the gained knowledge. This Framework can be generalizable to other types of projects.

As future perspectives, an empirical study of the VM framework object of this study can be led. Furthermore, a 


\section{International Journal of Engineering Applied Sciences and Technology, 2019 Vol. 4, Issue 8, ISSN No. 2455-2143, Pages 56-62 \\ Published Online December 2019 in IJEAST (http://www.ijeast.com)}

Value Planning process can be undertaken whilst the execution of the Green Digital Marketing Project. This Value Planning monitors the value of project besides, the reapplication of the elaborated VM Framework techniques at key milestones ensuring the value is on track.

Acknowledgment

$\mathrm{MoV}^{\mathrm{TM}}$ is a registered trademark of AXELOS Limited, used under permission of AXELOS Limited. All rights reserved.

\section{REFERENCE}

[1] Saaty, T. L. (1980). The Analytic Hierarchy Process: Planning, Priority Setting, Resource Allocation. New York, NY: McGraw-Hill.

[2] Miles, L. D. (1989). Techniques of Value Analysis and Engineering, 3rd ed. Eleanor Miles Walker.

[3] Thiry, M. (1997). A framework for value management practice. Sylva, NC: Project Management Institute.

[4] Blumstein, G. (2001). Fast diagramming - a technique to accelerate the gathering and interpreting the voice of the customer, Newtown Square, PA: Project Management Institute. Project Management Institute Annual Seminars \& Symposium, Nashville, TN.

[5] Roberts, R \& Goodwin, P. (2002). Weight approximations in multi-attribute decision models. Journal of Multi-Criteria Decision Analysis, Vol 11, No. 6, (pp. 291 - 303). 10. 02/mcda.320

[6] SAVE (2007). Value Methodology Standard and Body of Knowledge. Washington DC, USA.

[7] Axelos (2010). Management of Value $\left(\mathrm{MoV}^{\mathrm{TM}}\right)$. London, England: TSO.

[8] Lavalle, S., Lesser, E., Shockley, R., Hopkins, M. S., \& Kruschwitz, N. (2011). MIT Sloan Management Review, Big data Analytics and the Path From Insights to Value. MIT Sloan Management Review, Vol 52, No. 2, (pp. $21-31$ ).

[9] Cook, B., Gazzano, J., Gunay, Z., Hiller, L., Mahajan, S., Taskan, A., \& Vilogorac, S. (2012). The smart meter and a smarter consumer: Quantifying the benefits of smart meter implementation in the United States. Chemistry Central Journal, Vol 6 (S1), No. S5. https://doi.org/10.1186/1752-153X-6-S1-S5

[10] Fearne, A., Garcia Martinez, M., \& Dent, B. (2012). Dimensions of sustainable value chains: Implications for value chain analysis. Supply Chain Management: An International Journal, Vol 17, No. 6, (pp. 575 - 581). https://doi.org/10.1108/13598541211269193

[11] Phillips, J., \& Phillips, P. (2013). Measuring the Return on Investment on Green Projects and Sustainability
Efforts. Performance Improvement, Vol 52, No. 4, (pp. 38 - 52). https://doi.org/10.1002/pfi.21342

[12] Sánchez, L., Elicegui, I., Cuesta, J., Muñoz, L., \& Lanza, J. (2013). Integration of Utilities Infrastructures in a Future Internet Enabled Smart City Framework. Sensors, Vol 13, No. 11, (pp. 14438 - 4465). https://doi.org/10.3390/s131114438

[13] Berawi, M. A., Susantono, B., Miraj, P., Berawi, A. R. B., Rahman, H. Z., Gunawan, \& Husin, A. (2014). Enhancing Value for Money of Mega Infrastructure Projects Development Using Value Engineering Method. Procedia Technology, Vol 16, (pp. 10371046). https://doi.org/10.1016/j.protcy.2014.10.058

[14] Kelly, J., Male, S., \& Graham, D. (2015). Value Management of Construction Projects, 2nd ed. John Wiley \& Sons.

[15] Tiago, M. T. P. M. B., \& Veríssimo, J. M. C. (2014). Digital marketing and social media: Why bother?. Business Horizons, Vol 57, No. 6, (pp. 703-708). https://doi.org/10.1016/j.bushor.2014.07.002

[16] Silvius, A. J. G., \& Schipper, R. (2015). A Conceptual Model for Exploring the Relationship Between Sustainability and Project Success. Procedia Computer Science, Vol 64, (pp. 334-342). https://doi.org/10.1016/j.procs.2015.08.497

[17] Buxel, G. Esenduran, and S. Griffin, "Strategic sustainability: Creating business value with life cycle analysis. Business Horizons", 58(1), 109-122. https://doi.org/10.1016/j.bushor.2014.09.004. (2015)

[18] Engert, S., Rauter, R., \& Baumgartner, R. J. (2016). Exploring the integration of corporate sustainability into strategic management: A literature review. Journal of Cleaner Production, Vol 112, (pp. 2833-2850). https://doi.org/10.1016/j.jclepro.2015.08.031

[19] Rachwan, R., Abotaleb, I., \& Elgazouli, M. (2016). The Influence of Value Engineering and Sustainability Considerations on the Project Value. Procedia Environmental Sciences, Vol 34, (pp. 431-438). https://doi.org/10.1016/j.proenv.2016.04.038

[20] Kohl, K. (2016). Closing the gap between sustainable strategy and implementation. Newtown Square, PA: Project Management Institute. PMI® Global Congress 2016-EMEA, Barcelona, Spain.

[21] Carvalho, M. M., \& Rabechini, R. (2017). Can project sustainability management impact project success? An empirical study applying a contingent approach. International Journal of Project Management, Vol 35, No. 6, (pp. 1120-1132). https://doi.org/10.1016/j.ijpro man.2017.02.018

[22] Pappas, I. O., Mikalef, P., Giannakos, M. N., Krogstie, J., \& Lekakos, G. (2018). Big data and business analytics ecosystems: Paving the way towards digital 
transformation and sustainable societies. Information Systems and E-Business Management, Vol 16, No. 3, (pp. 479-491). https://doi.org/10.1007/s10257-0180377-z

[23] Yu, A. T. W., Javed, A. A., Lam, T. I., Shen, G. Q., \& Sun, M. (2018). Integrating value management into sustainable construction projects in Hong Kong. Engineering, Construction and Architectural Management. https://doi.org/10.1108/ECAM-03-20170049

[24] Manavalan, E., \& Jayakrishna, K. (2019). A review of Internet of Things (IoT) embedded sustainable supply chain for industry 4.0 requirements. Computers \& Industrial Engineering, Vol 127, (pp. 925-953). https://doi.org/10.1016/j.cie.2018.11.030

[25] Boulton, C. (2019). What is digital transformation? A necessary disruption. http://www.cio.com/article/32114 28/what-is-digital-transformation-a-necessarydisruption.html

[26] Khodeir, L. M., \& El Ghandour, A. (2019). Examining the role of value management in controlling cost overrun [application on residential construction projects in Egypt]. Ain Shams Engineering Journal, 10(3), 471479. https://doi.org/10.1016/j.asej.2018.11.008

[27] Alfian, G., Ijaz, M. F., Syafrudin, M., Syaekhoni, M. A., Fitriyani, N. L., \& Rhee, J. (2019). Customer behavior analysis using real-time data processing. Asia Pacific Journal of Marketing and Logistics. https://doi.org/10.1108/APJML-03-2018-0088

[28] Van Velthoven, M. H., \& Cordon, C. (2019). Sustainable Adoption of Digital Health Innovations: Perspectives From a Stakeholder Workshop. Journal of Medical Internet Research, Vol 21, No. 3. https://doi.org/10.2196/11922 